\title{
INVESTIGACIÓN/RESEARCH
}

\section{LA COBERTURA DE LA PRENSA EN TORNO A LA INSEGURIDAD MIGRATORIA DURANTE ELECCIONES PRESIDENCIALES}

Cruz García Lirios ${ }^{1}$ : Universidad Autónoma del Estado de México. México. garcialirios@terra.com

Javier Carreón Guillén: Universidad Nacional Autónoma de México. México. javierg@unam.mx

Jorge Hernández Valdés: Universidad Nacional Autónoma de México. México. jorheval@unam.mx

Miguel Bautista Miranda: Universidad Nacional Autónoma de México. México. miguelbautista76@hotmail.com

Agustín Méndez Martínez: Universidad Autónoma Metropolitana. México. amendez@hotmail.com

\section{RESUMEN}

La relevancia de la inseguridad migratoria parece cobrar un mayor auge en coyunturas tales como las elecciones presidenciales o parlamentarias en las que los precandidatos o candidatos insertan en su plataforma proselitista, el tema de la migración en referencia a la seguridad nacional. Tal proceso sociopolítico electoral es cubierto en mayor o menor medida por los medios de comunicación que, en el caso particular de la elección presidencial de México, parece corresponder con las pre-campañas internas en las cuales el tema de la inseguridad ha sido ubicua en lo general, pero soslayada la inseguridad migratoria en lo particular. En este sentido, se llevó a cabo un estudio retrospectivo con una muestra seleccionada de notas informativas en la prensa de circulación nacional. A partir de la Teoría del Establecimiento de la Agenda (TEA) y su ciclo de mediatización, se construyó un Índice de Mediatización de Inseguridad Migratoria (IMIM) para medir el sesgo de los medios impresos sobre la temática. Los resultados muestran que la cobertura de la inseguridad migratoria, durante el periodo que va de septiembre de 2011 a abril de 2012 es baja. Los hallazgos son discutidos a la luz de la TEA y su ciclo de mediatización.

PALABRAS CLAVE: Inseguridad - Migración - Ciclo - Contextualización Intensificación.

\footnotetext{
${ }^{1}$ Autor correspondiente:

Cruz García Lirios: Profesor del Departamento de Trabajo Social de la Universidad Autónoma del Estado de México. México.

Correo: garcialirios@terra.com
} 


\title{
PRESS COVERAGE REGARDING IMMIGRATION INSECURITY IN PRESIDENTIAL ELECTIONS
}

\begin{abstract}
A retrospective study was carried out with a selected sample of briefing notes in the press with national circulation. Based on the Establishment Setting Theory (EST) and its cycle of mediatization, an Index of Mediatization of Migratory Insecurity (IMMI) was built to measure the bias of the print media on the subject. The results show that the coverage of the migratory insecurity, during the period of September 2011 to April 2012 is low. The findings are discussed in the light of the TEA and its cycle of mediatization.
\end{abstract}

KEYWORDS: Insecurity - Migration - Cycle - Setting - Priming.

\section{INTRODUCCIÓN}

La inseguridad pública y los procesos migratorios son temas centrales de la agenda nacional e internacional de los países económicamente desarrollados y emergentes. En el caso de México, en relación con América Central y los Estados Unidos de América (EUA), la inseguridad alude a la violencia hacia los migrantes centroamericanos y mexicanos en su transitar hacia los EUA. Tal violencia ha tenido una amplia cobertura en los medios impresos internacionales más que nacionales (Gunter, 2008).

Al ser un tema central en la agenda económica, política y social, la inseguridad migratoria debiera ser un tema relevante en campañas pre-electorales y electorales. En el caso de México, la inseguridad migratoria fue un tema central antes de las precampañas. Los acontecimientos de secuestro y asesinatos de migrantes centroamericanos por parte de grupos narcotraficantes incluyeron en la agenda pública la inseguridad migratoria. Sin embargo, una vez iniciadas las pre-campañas, los discursos proselitistas no han incluido los temas críticos de la migración centroamericana hacia EU a través de México.

Si las pre-campañas se enfocan en otros temas exógenos a la inseguridad migratoria, si la cobertura de la prensa soslaya las noticias relativas a los riesgos del transitar por México hacia los Estados Unidos enmarcando sus noticias a las declaraciones de los pre-candidatos, sus equipos proselitistas y partidos políticos, entonces estaríamos ante el establecimiento de una agenda proselitista en la que los medios de comunicación realizan una cobertura sesgando sus contenidos para manipular a sus audiencias al reducir la importancia de la inseguridad migratoria.

\subsection{Teoría del Establecimiento de la Agenda}


Los postulados de la Teoría del Establecimiento de la Agenda permiten explicar el proceso de construcción de la agenda mediática, pública y sobre todo política en torno a la inseguridad, la violencia, los homicidios y la impunidad. La Teoría del Establecimiento de la Agenda (TEA) asegura que los medios de comunicación difunden temas de violencia a partir de sus intereses y no de la tendencia de casos del fuero común o federal. Dicha prevalencia tiene un efecto sobre la percepción de inseguridad de las audiencias y en el caso de los medios impresos, el efecto es el discurso de sus lectores sobre la violencia y particularmente, los homicidios dolosos.

Por una parte, los estudios mediáticos han demostrado la selección, fragmentación y sesgo del ejercicio periodístico con estudios de sondeo simultáneo en el que las percepciones de los encuestados son una extensión de la agenda de los medios. Por otra parte, los experimentos de recepción y percepción corroboran no sólo el sesgo informático, sino además su poder de influir en la opinión púbica. No obstante, la TEA refiere solamente al sesgo informativo sin precisar un tiempo y espacio definidos para su comprobación empírica. En efecto, la tendencia ha sido medir simultáneamente, durante un lapso de tiempo determinado, el sesgo mediático y la influencia en la percepción de la gente.

Sin embargo, no es posible realizar dos diagnósticos simultáneos de los hechos y concluir que existe una relación directa y significativa entre ellos. Si partimos de la premisa en torno a la cual un hecho es observable simultáneamente más de una vez, entonces tendríamos que pensar que la percepción si y sólo si está influida por los medios, olvidando que puede estar influida por el hecho en sí, por otros acontecimientos relacionados, por experiencias directas, indirectas e incluso por otras notas informativas.

El mismo Maxwell McCombs (1972) sostiene que el sesgo informativo es inherente al ejercicio periodístico y esto significa que en realidad los medios no influyen directamente en la agenda pública. Es decir, los medios son sólo depositarios de los errores del ejercicio periodístico.No obstante, Cervantes (1999) crítica el planteamiento de McCombs en torno al establecimiento de la agenda-setting como fases no inductivas en las que sólo se consideran las noticias externas susceptibles de ser codificadas para demostrar la incidencia de los medios de comunicación en la opinión pública.

La Teoría del Establecimiento de la Agenda estaría más cercana al análisis de las noticias internacionales que la opinión pública no puede conocer directamente y por ello se ve sumamente influenciada por los medios de comunicación dado que otras fuentes de información, incluso Internet, no ofrecen contenidos cercanos al entendimiento de las personas comunes y corrientes que aprenden con base en imágenes más que con discursos estructurados o razonamientos lógicos científicos (Penalva, 1999). Al construir una agenda mediática, los medios de comunicación construyen una agenda pública y política esencial para el Estado (Vázquez, 2004). Es decir, los medios de comunicación utilizan marcos de referencia en los que la opinión 
pública se basa para construir su agenda de discusión pública. Se trata de atributos en torno a un tema que orientan la percepción, selección y recepción de la información por parte de las audiencias. El establecimiento de la agenda es un efecto de resonancia informativa en el que los medios emiten temas que a posteriori las audiencias amplificaran o disminuirán su relevancia, pero en definitiva incluirán en su agenda de discusión una vez que los medios se han encargado de difundir la noticia (García, 2007).

En este sentido, la agenda es una colección de temas compartidos por comunicadores, políticos y audiencias. No obstante, los estudios sobre el establecimiento de la agenda se enfocan en el proceso por el cual los medios de comunicación seleccionan los temas que las audiencias recepcionaran como de suma importancia y posteriormente discutirán con base en los conceptos difundidos por los medios (Muñiz, 2007).

De León (2008) sostiene que los medios de comunicación invisten de atributos los temas para facilitar su inclusión en la agenda pública. A través de los titulares y encabezados, los medios masivos de comunicación difunden expectativas en sus audiencias. Esto corrobora la hipótesis en torno a la cual los medios de comunicación influyen en la sociedad produciendo temas y colocándolos en la agenda de discusión pública. Los medios de comunicación masiva determinan y dictan los temas que la gente comentará. La opinión pública construirá percepciones sobre la importancia de los temas expuestos en los medios. Posteriormente, la gente comentará los temas incluso con las palabras utilizadas por los profesionales de la comunicación en televisión, radio, prensa e internet (Igartua, Muñiz, Otero, Cheng y Gómez, 2008).

Por su parte, Luengo (2009) relaciona el establecimiento de la agenda con la formación de actitudes y decisiones de discusión en torno a los temas seleccionados por los medios y aceptados por la opinión pública como los asuntos públicos de mayor interés e importancia. Se trata de un efecto mediático que construye la opinión pública a través de sus expectativas e intenciones de llevar a cabo una discusión pública al interior del grupo de referencia o pertenencia. El establecimiento de la agenda pública se construye con estrategias de contexto tales como; mayor primacia, cobertura, tiempo y espacio a noticias relativas. En esto consistiría el poder mediático ya que los medios de comunicación pueden enfatizar un tema sin tener que asumir riesgos (Obregón, Arroyave y Milena, 2009).

Ugarte, Menéndez y Cuesta (2009) critican el énfasis político en los temas que permitieron corroborar la hipótesis del establecimiento de la agenda. Reducen a las audiencias a meros espectadores incapaces de seleccionar información y construir su agenda de discusión. Paradójicamente, McCombs (1972), a decir de los autores, concluye perfilando la investigación hacia los efectos psicológicos de los medios de comunicación en la opinión pública. Finalmente, la agenda es un problema social, a menudo conflictivo, que ha recibido cobertura mediática sesgando la atención del público hacia determinados objetos o cuestiones de la escena política y social en los que el público confía y asigna importancia en función del grado de relevancia mediático (Chihú, 2011). 
La Teoría del Establecimiento de la Agenda explica procesos representacionales y emocionales. Tanto los símbolos como las imágenes son, según los estipula la TEA, el resultado de un proceso improvisado y heurístico en el que las percepciones, creencias, actitudes, decisiones y comportamientos están determinados por la mediatización de un hecho. La TEA sugiere que los medios de comunicación masiva o mass media, se rigen por una lógica de mercado y a partir de minimizar costos para maximizar beneficios, sesgan la información y la transforman en noticias. Reducen los hechos a simples reportajes, spots, entrevistas, columnas, opiniones o slogans.

El impacto de la contextualización, enmarcado e intensificación de las noticias sobre la opinión pública es propiciado por el sesgo informativos de los medios de comunicación. En la medida en que son seleccionadas las noticias, la representación y el procesamiento de la información tienden a objetivarse en emociones. Una vez contextualizada y enmarcada una noticia, se inicia un proceso de persuasión marcado por la necesidad de escuchar los pormenores de las noticias, el electorado ha objetivado y naturalizado el contenido de dichos mensajes para resguardar su significado en un anclaje representacional (McCombs, 1996). La objetivación se refiere a la traducción en imágenes de las noticias y la naturalización alude a su aceptación y adopción como una realidad externa al control individual.

Los medios de comunicación son representados como guías de valores, discursos, decisiones y comportamientos por parte de la ciudadanía. Ayer los mensajes sesgados definían el significado de una representación política; hoy, los símbolos mediatizados son afectos o emociones y, en tanto tales, introducen expectativas de procesamiento de información. Precisamente, este es el fundamento de la mediatización, como símbolos persuasivos, los mensajes sesgados determinan su recepción. El encuadre de un hecho en una noticia incide en la representación afectiva de imágenes. Se trata de una objetivación y naturalización de símbolo conocidos por la opinión pública gracias a la difusión intensiva. Dado que los símbolos son inconmensurables, las respuestas también son impredecibles.

A pesar de que la TEA no plantea un ciclo de mediatización en la que se explicite cómo los medios de comunicación aumentan o disminuyen su sesgo informativo, es posible construirlo para el caso de la inseguridad migratoria si se considera que la TEA explica la naturalización de imágenes en la cobertura de los hechos. El ciclo incluiría diez fases en las que es posible ubicar el sesgo informativo de los medios de comunicación masiva (ver figura 1).

Las fases incluyen inseguridad; agresión, injuria, injusticia, ansiedad, peligro, desesperación, pánico, depresión, venganza y discriminación. Cada una de ellas alude a una espiral de violencia en la que los medios de comunicación sustentan sus encabezados y contenidos de información. En el caso de la prensa, el ciclo de mediatización sería un conjunto de criterios en los que cada nota informativa puede ponderarse e interpretarse. En la medida en que la espiral de la violencia continúa la asignación de su valor también se incrementa. Es decir, las audiencias, en el caso de 
la prensa, los lectores, naturalizan los sesgos informativos a partir de las fotografías que ilustran la nota informativa. Tal naturalización sería identificada como "espiral de violencia".

\section{METODOLOGÍA}

Se realizó un estudio exploratorio y retrospectivo en el que se analizaron las noticias relativas la inseguridad que experimentan los migrantes en su trayectoria y que ha sido reportada por la prensa nacional durante el periodo que va de septiembre de 2011 a abril de 2012. Se establecieron estas fechas debido a que durante ellas, la cobertura de los medios de comunicación en general y los medios impresos en particular se concentraron en las pre-campañas electorales en cuya agenda, la violencia y la migración indicaban la política interna y externa de México con respecto a EUA y Centroamérica.

Se seleccionaron 11 noticias de periódicos de circulación nacional. Se consideraron sólo aquellas notas informativas que documentaban extractos de entrevistas relativas a migrantes afectados por la inseguridad.

Se utilizaron matrices de análisis de contenido ponderativas en las que se incluye la fecha, titulo, extracto y clasificación de las noticias seleccionadas. Dicha matriz permite la suma de las ponderaciones asignadas a cada nota informativa. Una vez sumadas, se establece el Índice de Mediatización de la Inseguridad Migratoria (IMIM). En virtud de que las noticias recaban y en muchos casos fundamentan el contexto, encuadre, intensidad y dirección de la información a partir de las declaraciones de los afectados, se asignó un valor de 0 a aquellas notas que incluyen entrevistas en las que no se pronuncia siquiera un sinónimo de los conceptos alusivos a la espiral de violencia, 1 a aquellas notas que incluyen declaraciones sobre inseguridad, 2 a aquellas notas que incluyen declaraciones sobre agresión, 3 a declaraciones de injuria, 4 a declaraciones de injusticia, 5 a declaraciones de ansiedad, 6 a declaraciones de peligro, 7 a declaraciones de pánico, 8 a declaraciones de depresión, 9 a declaraciones de venganza, 10 a declaraciones de discriminación. Si se trataba de una contextualización, se multiplicaba el total por 1 , si se trataba de un enmarcado se multiplicaba por 2 y si se trataba de una propaganda se multiplicaba por 3 . El criterio de multiplicación obedece a que la mediatización que consiste en contextualizar la noticia con datos tiene menor impacto que las noticias encuadradas en un aspecto socioeconómico o sociopolítico y aquellas que difunden propaganda dirigida al conflicto con miras al cambio social.

Una vez ponderadas las noticias, fueron sumadas sus codificaciones para ubicarlas en un subíndice de mediatización que se establece mediante el criterio de nula mediatización (cero puntos), muy baja mediatización (menos de 300), baja mediatización (entre 301 y 400), mediana mediatización (entre 401 y 500), alta mediatización (entre 501 y 600) muy alta mediatización (más de 600). Los criterios surgen a partir del concepto de Mediatización de la Inseguridad Migratoria en la que se sugiere un continuo de que va de la nulidad hasta la mediatización extrema. Es 
decir, la prensa recopila las declaraciones sobre agresión, injuria, injusticia, ansiedad, peligro, desesperación, pánico, depresión, venganza y discriminación que pueden indicar el nivel de inseguridad registrado por la prensa.

Se realizó una búsqueda avanzada a través de google.com. Los criterios fueron: periódicos de circulación nacional, fecha de la noticia dentro del umbral enero de 2010 a abril de 2012, encabezado de la noticia relacionado con la inseguridad y la migración. Posteriormente, se seleccionaron las notas informativas a partir de sus contenidos contextuales, enmarcados e intensificación de sus reportajes, opiniones, entrevistas o análisis. Se vació la información en matrices de análisis (ver anexo) y se procedió a calificar en contenido de las notas seleccionadas.

\section{ANÁLISIS Y DISCUSIÓN}

La tabla 1 muestra las categorías de inseguridad migratoria y los niveles de análisis del contenido de éstas. De acuerdo con los resultados, la categoría peligro obtuvo el mayor puntaje de mediatización al alcanzar la cifra de 100 puntos seguida de la categoría discriminación con 40 punto de mediatización.

Ambas categorías reflejan el significado de la inseguridad migratoria, puesto que el peligro y la discriminación son dos fases permanentes de la espiral violenta hacia quienes transitan por México y se dirigen hacia los Estados Unidos de América.

En contraste, las categorías desesperación, depresión, venganza no son siquiera mencionadas por las notas de prensa. Llama la atención la ausencia de mediatización de las noticias de estas categorías, puesto que parecen indicar que en México, los periódicos de circulación nacional, durante el periodo de análisis elegido, no reportan los sentimientos de desesperación, depresión y venganza de los implicados en la inseguridad migratoria, las opiniones y análisis de los expertos no parecen considerar éstas tres emociones y los periodistas no parecen orientar sus entrevistas a estos afectos.

A partir de la Teoría del Establecimiento de la Agenda, es posible afirmar que los medios de comunicación impresos sesgan los contenidos de sus noticias sobre la inseguridad migratoria contextualizando, enmarcando e intensificando el peligro y la discriminación. Sin embargo, una vez sumados todos los sesgos, el Índice de Mediatización de la Inseguridad Migratoria (IMIM) alcanzó los 213 puntos ubicándose en un nivel bajo de mediatización. Esto significa que la prensa sesga discretamente los contenidos de sus noticias. La baja mediatización de los periódicos La Jornada y El Universal no sería suficiente para influir en la opinión pública, la clase política, las agendas ciudadana, política y pública.

De acuerdo con el ciclo de la inseguridad, el IMIM parece indicar que la inseguridad migratoria se encuentra en el inicio de la fase de peligro. Este hallazgo es relevante para la discusión de las políticas públicas en materia migratoria. Dado que la mediatización indica que la inseguridad migratoria se ubica al principio de la quinta fase del ciclo, entonces será posible revertir la tendencia al reducir los riesgos con la 
presencia de las fuerzas públicas. En tal sentido, la coerción de la policía y el ejército en torno al combate de la inseguridad migratoria estaría justificada al menos en términos mediáticos. No obstante, el ciclo de la inseguridad migratoria es sumamente complejo. El IMIM recaba dicha complejidad al advertir que mientras en algunas fases del ciclo la prensa no reporta sucesos o hechos relacionados, en otras fases, la prensa concentra sus contextualizaciones, enmarcados e intensificaciones para influir en la opinión pública.

\section{CONCLUSIONES}

El presente trabajo ha demostrado una baja mediatización de la inseguridad migratoria considerando el IMIM, el cual ubica con un mínimo sesgo a las noticias de los medios impresos seleccionados considerando las pre-campañas para la elección de presidente en México.

El contexto pre-electoral de México parece coincidir con la baja mediatización de la inseguridad migratoria a pesar de que fue un tema central en la agenda nacional e internacional dado el tránsito de migrantes centroamericanos hacia los Estados Unidos. En este sentido, los medios impresos no sólo han reducido sus notas con respecto al periodo anterior a las pre-campañas, sino además la mediatización contextualización, enmarcamiento e intensificación-también se ha reducido a un nivel bajo. Es decir, ante un suceso, acontecimiento o hecho de inseguridad migratorio, los medios impresos sólo se ocupan de difundir la noticia sin tratar de influir en la opinión pública o la agenda pública.

El bajo sesgo en las noticias alusivas a la inseguridad migratoria hace pensar que la mediatización de los periódicos parece haberse trasladado a otros temas relacionados con las pre-campañas como los casos de corrupción. Si los medios impresos sesgan otros temas relacionados con los pre-candidatos, entonces se cumpliría en parte un postulado esencial de la Teoría del Establecimiento de la Agenda que consiste en la influencia parcial de los medios de comunicación masiva sobre las audiencias.

En tal sentido, un estudio sobre la mediatización de temas relacionados con precampañas de pre-candidatos podría esclarecer el bajo o alto sesgo de la inseguridad migratoria durante este periodo pre-electoral. No obstante, la cantidad de temas que los medios de comunicación abordan parece protegerlos del análisis de sus sesgos. En una ciudad como la de México donde cerca de una veintena de periódicos diversifican aún más las noticias sobre varios temas, los análisis de mediatización pueden considerar a las coyunturas sociopolíticas para evidenciar el sesgo y su grado de mediatización. Tal heterogeneidad se intensifica si se toma en cuenta que el IMIM mide frecuencias de rasgos psicológicos que nos harían pensar en una mediatización de segundo orden puesto que los hechos no sólo son sesgados por la cobertura periodística, además los individuos seleccionan la información a partir de criterios heurísticos más que racionales. Por ello las pre-campañas y, más aún, las campañas electorales son una sumatoria de mediatizaciones en las que las imágenes parecen tener un mayor impacto que los discursos. 


\section{BIBLIOGRAFÍA}

Cervantes, C. (1999). La sociología de las noticias como vía para renovar la investigación en la línea agenda-setting: revisión de interpretaciones. Comunicación y Sociedad. $36,133-152$

Chihú, A. (2011). El Framing del spot político. México: UAM-Porrúa

De León, S. (2008). Notas para una exploración teórica sobre los estudios de producción de comunicación mediática (periodismo, opinión pública y comunicación política). Comunicación y Sociedad. 9, 145-173

Francisco, M., García, M. y Maya, I. (2001). El efecto amortiguador del apoyo social sobre la depresión en un colectivo de inmigrantes. Psicothema. 13, 605-610

García, J. (2007). El comportamiento de la prensa durante los conflictos de Kosovo e Irak. Tesis de Doctorado. Universidad de Granada

García, M., Martínez, M. y Albar, M. (2002). La elección de fuentes de apoyo social entre inmigrantes. Psicothema. 14, 369-374

Gunter, B. (2008). Media violence: Is there a case for causality? American Behavioral Scientist. 51 (8), 1061-1022

Gutiérrez, A. (2004). Discursos juveniles sobre inmigración: un análisis psicosociológicos en estudiantes. Psicothema. 16, 384-390

Igartua, Juan., Muñiz, Carlos., Otero, José., Cheng, Lifen y Gómez, José. (2008). Recepción en impacto socio-cognitivo de las noticias sobre inmigración. Revista de Psicología Social. 23, 3-16

Kondratieff, N. (1920/2004). The world economy and its conjunctures during and after the war. Moscú: IKF

Lozano, M. (2004). Aspectos psicológicos, sociales y jurídicos del desplazamiento forzoso. Acta Colombiana de Psicología. 12, 103-119

Luengo, M. (2009). Desde los "efectos" mediáticos hasta la influencia cultural: fundamentos analíticos para la interpretación simbólica de los medios. Análisis. 39, 113-129

McCombs. M. (1972). The agenda-setting function of mass media. The public Opinion Quarterly. 36, 176-187

McCombs, M. (1996). Influencia de las noticias sobre nuestras imágenes del mundo. En Jennings, B. y D. Zillmann (coord.) Los efectos de los medios de comunicación: 
investigaciones y teorías. (pp. 12-31).Barcelona: Paidós.

Muñiz, C. (2007). Encuadres noticiosos e inmigración: del análisis de los contenidos al estudio de los efectos mediáticos. Tesis de Doctorado. Universidad de Salamanca

Obregón, R., Arroyave, J. y Milena, M. (2009). Cubrimiento periodístico de la gestión del riesgo en la subregión andina. Discursos periodísticos y perspectivas de la comunicación para el cambio social. Perú: Comunidad Andina

Penalva, C. (1999). La selección de noticias como indicador de desigualdad entre naciones. Papers. 59, 155-172

Pineda, A. (2007). ¿Todo es propaganda? El propagandismo o monismo propagandístico como límite superior de la teoría de la propaganda. Comunicación. 5, 415-436

Ugarte, A., Menéndez, T. y Cuesta, U. (2009). Prensa escrita y salud en Madrid. España: Universidad Complutense de Madrid

Vázquez, A. (2004). La realidad de los medios de comunicación. Comunicación y Sociedad. 2, 247-273

\section{Cruz García Lirios}

Psicólogo Social, Universidad Autónoma Metropolitana. Estudiante de maestría en Trabajo Social y doctorado en Psicología Social, Universidad Nacional Autónoma de México. Profesor adscrito a la Universidad Autónoma del Estado de México, Unidad Académica Profesional Huehuetoca. Autor del libro: Hidroexclusión publicado por la Universidad de Málaga ISBN 978-84-695-2399-5 Integrante de la Asociación Latinoamericana de Sociología Rural (ALASRU), Red Nacional de Investigación Urbana (RNIU), Asociación Mexicana de Hidraúlica (AMH), Asociación latinoamericana de Estudios e Investigación en Trabajo Social (ALEITS), Red Internacional de Investigación en Competitividad en Organizaciones Educativas (RICOE), Asociación Mexicana de Ciencias para el Desarrollo Regional (AMECIDER), Asociación Latinoamericana de Psicología de la Salud (ALAPSA).

\section{Javier Carreón Guillén}

Licenciado en Historia y doctor en Administración, Universidad Nacional Autónoma de México. Maestro en administración, Universidad Autónoma Metropolitana. Adscrito al Sistema Nacional de Investigadores (SIN nivel I). Profesor en Escuela nacional de Trabajo Social. Coordinador y coautor del libro: Psicología de la Globalización Neoliberal. ISBN 978-84-9969-213-5

\section{Jorge Hernández Valdés}

Licenciado en Trabajo Social, Universidad Nacional Autónoma de México. Profesor en Escuela Nacional de Trabajo Social. Coordinador y coautor del libro: Psicología de la Globalización Neoliberal. ISBN 978-84-9969-213-5 


\section{Miguel Bautista Miranda}

Licenciado y maestro en Trabajo Social, Universidad Nacional Autónoma de México. Profesor en Universidad Autónoma del Estado de México, Unidad Académica Profesional Chimalhuacán. Coautor del libro: Psicología de la Globalización Neoliberal. ISBN 978-84-9969-213-5

\section{Agustín Méndez Martínez}

Licenciado en Psicología Social, Universidad Autónoma Metropolitana. Profesor de la Secretaria de Educación Pública. Coautor del libro: Psicología de la Globalización Neoliberal. ISBN 978-84-9969-213-5

\section{ANEXO}

Figura 1. Ciclo de la Mediatización de Inseguridad 


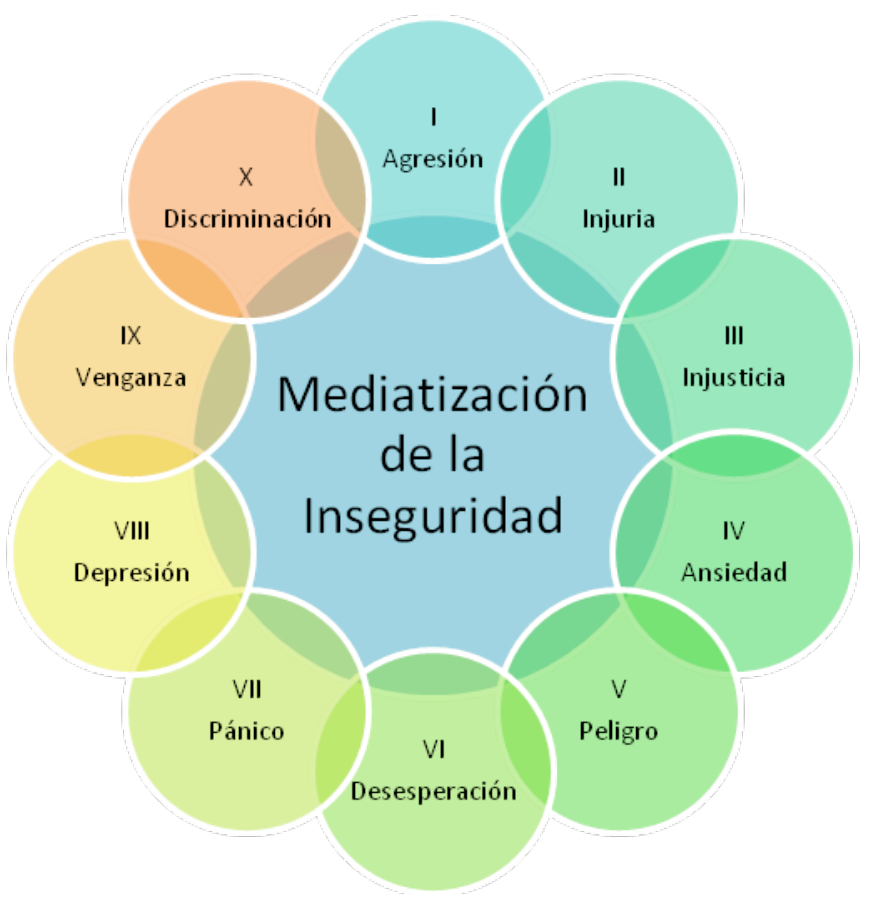

Fuente: Elaboración propia con base en el ciclo económico de Kondratieff (1920/2004)

\section{GLOSARIO}

Categorías. La elaboración del presente estudio considero las fases de la inseguridad; agresión, injuria, injusticia, ansiedad, peligro, desesperación, pánico, depresión, venganza y discriminación.

La agresión fue definida como un acto deliberado, alevoso y ventajoso de una persona o grupo expuesto en la prensa como delincuente hacia una persona o grupo migrante considerado como víctima.

La injuria es un delito incentivado por alguna de las partes en conflicto de intereses y expuesta por la prensa como acusaciones directas e indirectas de una persona 0 grupo hacia otro individuo o grupo (Gutiérrez, 2004).

La injusticia alude a las percepciones sesgadas de enjuiciamiento y condena de los migrantes agraviados en referencia a sus ofensores y cuyos resultados no les favorecen según la opinión de periodistas (Lozano, 2004).

La ansiedad refiere a un estado emocional de bajo autocontrol en torno al cual los periodistas y reporteros atribuyen como causa psicológica de la comisión de un delito y como una consecuencia psicológica de los migrantes víctimas del delito (García, Martínez y Albar, 2002). 
El peligro incluye percepciones y sentimientos de impotencia de los migrantes ante los hechos delictivos en torno al cual, la prensa etiqueta a un espacio, proceso, persona $o$ grupo.

La desesperación es mediatizada como un estado de ánimo en el que los migrantes víctimas declaran a la prensa sus emociones relativas a buscar un ser querido raptado, recuperar el patrimonio que le han hurtado o revivir a la persona asesinada.

El pánico alude a una emoción que la prensa califica como extrema para describir la supervivencia de los migrantes víctimas potenciales de la delincuencia (Pineda, 2007).

La depresión denota un estado emocional en el que los migrantes víctimas o potenciales victimas acuden a refugiarse para afrontar los delitos que han padecido y aquellos que estiman sufrir en el futuro según las noticias de la prensa (Francisco, García y Maya, 2001).

La venganza es una emoción que la prensa identifica como un incentivo para la comisión de un delito por parte del migrante hacia raptores, homicidas, ladrones, embaucadores, estafadores o extorsionadores.

La discriminación refiere a discursos y acciones que la prensa codifica como causas y efectos de la inseguridad en un espacio delimitado y tiempo determinado al termino de los cuales, los rotativos esperan una espiral de violencia.

\section{Tabla 1. Índice de Mediatización de la Inseguridad Migratoria}

\begin{tabular}{|c|c|c|c|c|c|c|}
\hline Inseguridad & $\begin{array}{l}\text { Valor } \\
\text { acumulado }\end{array}$ & Contextualización & Enmarcado & Intensificación & $\begin{array}{c}\text { Total } \\
\end{array}$ & Interpretación \\
\hline Nulidad & 0 & 0 & 0 & 0 & 0 & $\begin{array}{l}\text { Las noticias seleccionadas } \\
\text { incluyen mediatizaciones } \\
\text { que no pueden ubicarse en } \\
\text { un nivel de nulidad. }\end{array}$ \\
\hline Agresión & 1 & $1(1)=1$ & $1(0)=0$ & $1(0)=0$ & 1 & $\begin{array}{lll}\text { La fase de agresión } & \text { sólo } \\
\text { incluyó un un caso } \\
\text { contextualizado. }\end{array}$ \\
\hline Injuria & 0 & $2(0)=0$ & $2(0)=0$ & $2(0)=0$ & 0 & $\begin{array}{l}\text { Las noticias seleccionadas } \\
\text { no incluyen la injuria } \\
\text { mediatizada en } \\
\text { contenidos. }\end{array}$ \\
\hline Injusticia & $3+3=6$ & $3(1)=3$ & $3(2)=6$ & $3(0)=0$ & 15 & $\begin{array}{l}\text { Dos noticias presentan } \\
\text { contenidos relativos a la } \\
\text { injusticia }\end{array}$ \\
\hline Ansiedad & 4 & $4(1)=4$ & $4(2)=8$ & $4(3)=12$ & 28 & $\begin{array}{l}\text { Sólo un caso de las once } \\
\text { noticias incluyó a la } \\
\text { ansiedad contextualizada, } \\
\text { enmarcada e intensificada. }\end{array}$ \\
\hline Peligro & $5+5+5+5=20$ & $\begin{array}{l}5(1)+5(1)+5 \\
(1)+5(1)=20\end{array}$ & $\begin{array}{l}5(2)+5 \\
(2)+5(2) \\
\quad=30\end{array}$ & $\begin{array}{c}5(3)+5(3) \\
=30\end{array}$ & 100 & $\begin{array}{l}\text { Cuatro casos de } \\
\text { mediatización relativa al } \\
\text { peligro contextualizado, }\end{array}$ \\
\hline
\end{tabular}




\begin{tabular}{|c|c|c|c|c|c|c|}
\hline & & & & & & enmarcada e intensificado. \\
\hline Desesperación & 0 & 0 & 0 & 0 & 0 & $\begin{array}{l}\text { Ningún caso de } \\
\text { mediatización de la } \\
\text { desesperación en torno a la } \\
\text { inseguridad migratoria }\end{array}$ \\
\hline Pánico & 7 & $7(1)=7$ & $7(2)=14$ & $7(0)=0$ & 28 & $\begin{array}{l}\text { Sólo un caso relativo a la } \\
\text { mediatización del pánico } \\
\text { contextualizado } \\
\text { enmarcado }\end{array}$ \\
\hline Depresión & 0 & 0 & 0 & 0 & 0 & $\begin{array}{l}\text { Ningún caso de depresión } \\
\text { mediatizada en torno a la } \\
\text { inseguridad de migrantes }\end{array}$ \\
\hline Venganza & 0 & 0 & 0 & 0 & 0 & $\begin{array}{l}\text { Ningún caso de } \\
\text { mediatización de venganza } \\
\text { relativo a la inseguridad de } \\
\text { migrantes }\end{array}$ \\
\hline Discriminación & $10+10=20$ & $\begin{array}{c}10(1)+10(1)= \\
20\end{array}$ & $10(0)=0$ & $10(0)=0$ & 40 & $\begin{array}{l}\text { Dos caso de mediatización } \\
\text { de la discriminación que } \\
\text { sólo fueron enmarcados } \\
\text { por las notas de prensa. }\end{array}$ \\
\hline Total & 58 & 55 & 58 & 42 & 213 & $\begin{array}{l}\text { Muy baja mediatización de } \\
\text { la inseguridad migratoria. } \\
\text { Las noticias relativas a la } \\
\text { inseguridad migratoria se } \\
\text { enfocan en el peligro como } \\
\text { su contenido esencial y el } \\
\text { enmarcado como su sesgo } \\
\text { principal. }\end{array}$ \\
\hline
\end{tabular}

Fuente: Elaborada con los datos del estudio

Nota: El valor de cada noticia es determinado por su nulidad $=0$, agresión $=1$, injuria $=2$, injusticia $=3$, ansiedad $=4$, peligro $=5$, desesperación $=6$, pánico $=7$, depresión $=8$, venganza $=9$ y discriminación $=10$. Cada valor es multiplicado por su contextualización $=1$, enmarcado $=2$ e intensificación $=3$ del extracto periodístico. Al final se suman los productos y se establece el Índice de Mediatización de la Inseguridad Migratoria

Tabla 2. Matriz de ponderación de la mediatización de la Inseguridad Migratoria

\begin{tabular}{|c|c|c|c|c|c|c|c|c|c|c|}
\hline 送 & $\sum^{\mathscr{\varrho}}$ & 范 & 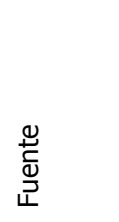 & $\begin{array}{l}\frac{\pi}{0} \\
\frac{0}{0} \\
\frac{0}{2}\end{array}$ & 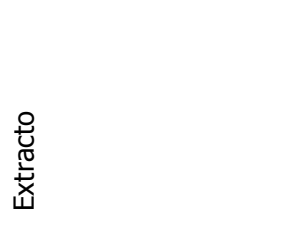 & 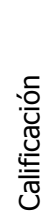 & 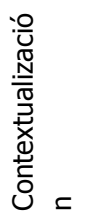 & 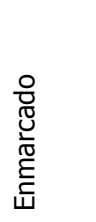 & 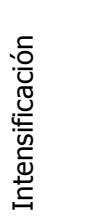 & $\begin{array}{l}\bar{\pi} \\
\stackrel{0}{0}\end{array}$ \\
\hline 2011 & Septiembre & 6 & $\begin{array}{l}\text { La } \\
\text { Jornada }\end{array}$ & $\begin{array}{l}\text { ¿Nueva } \\
\text { estrategia } \\
\text { Migratoria? }\end{array}$ & $\begin{array}{l}\text { Las muertes en la } \\
\text { frontera disminuyeron } \\
\text { de } 234 \text { a } 168 \text { en éste } \\
\text { año fiscal y eso de } \\
\text { debe, según Bersain a } \\
\text { que han enviado el } \\
\text { mensaje de que la } \\
\text { frontera es mucho } \\
\text { más fuerte con la } \\
\text { presencia de los } \\
\text { agentes. }\end{array}$ & 1 & $\begin{array}{l}1 \text { (1) } \\
=1\end{array}$ & $\begin{array}{l}1(0) \\
=0\end{array}$ & $\begin{array}{l}1(0) \\
=0\end{array}$ & 2 \\
\hline
\end{tabular}




\begin{tabular}{|c|c|c|c|c|c|c|c|c|c|c|}
\hline 2011 & Septiembre & 6 & $\begin{array}{l}\text { La } \\
\text { Jornada }\end{array}$ & $\begin{array}{l}\text { ¿Nueva } \\
\text { estrategia } \\
\text { Migratoria? }\end{array}$ & $\begin{array}{l}\text { Desde la década de } \\
1990 \quad(\ldots) \text { los } \\
\text { indocumentados se } \\
\text { incrementaron a } 12 \\
\text { millones, de los cuales } \\
\text { cerca de } 7 \text { millones } \\
\text { son mexicanos. Había } \\
\text { trabajo y por eso valía } \\
\text { la pena arriesgarse, } \\
\text { pues las condiciones } \\
\text { laborales en México } \\
\text { eran lamentables. }\end{array}$ & 4 & $\begin{array}{l}4(1) \\
=4\end{array}$ & $\begin{array}{l}4 \quad(2) \\
=8\end{array}$ & $\begin{array}{l}4 \quad(3) \\
=12\end{array}$ & 28 \\
\hline 2012 & Marzo & 19 & $\begin{array}{l}\text { La } \\
\text { Jornada }\end{array}$ & $\begin{array}{l}\text { Programa de } \\
\text { piloto de } \\
\text { repatriación } \\
\text { de migrantes } \\
\text { desde } \\
\text { Estados } \\
\text { Unidos } \\
\text { costara } 50 \\
\text { millones de } \\
\text { dólares: } \\
\text { Instituto } \\
\text { Nacional de } \\
\text { Migración }\end{array}$ & $\begin{array}{l}\text { Se trata, explicaron } \\
\text { ambos funcionarios de } \\
\text { romper la cadena de } \\
\text { corrupción en la } \\
\text { frontera común para } \\
\text { evitar con ello que los } \\
\text { deportados en esa } \\
\text { zona sean víctimas de } \\
\text { las organizaciones } \\
\text { criminales, quienes } \\
\text { "los enganchan" para } \\
\text { el trasiego de drogas, } \\
\text { la trata y la extorsión } \\
\text { entre otros. }\end{array}$ & 5 & $\begin{array}{l}5 \quad(1) \\
=5\end{array}$ & $\begin{array}{l}5(0) \\
=0\end{array}$ & $\begin{array}{l}5(0) \\
=0\end{array}$ & 10 \\
\hline 2012 & Febrero & 29 & $\begin{array}{l}\text { La } \\
\text { Jornada }\end{array}$ & $\begin{array}{l}\text { Se piensa } \\
\text { que la } \\
\text { migración } \\
\text { externa es } \\
\text { causa de la } \\
\text { inseguridad: } \\
\text { CONAPRED }\end{array}$ & $\begin{array}{l}80 \text { por ciento de la } \\
\text { población general } \\
\text { opina que los } \\
\text { derechos de las } \\
\text { personas migrantes no } \\
\text { se respetan o se } \\
\text { respetan poco (...) el } \\
\text { desempleo, seguido } \\
\text { de la discriminación e } \\
\text { inseguridad fueron } \\
\text { considerados los } \\
\text { principales problemas }\end{array}$ & 10 & $\begin{array}{l}10 \\
(1)= \\
10\end{array}$ & $\begin{array}{l}10 \\
(0== \\
0\end{array}$ & $\begin{array}{l}10 \\
(0)= \\
0\end{array}$ & 20 \\
\hline 2012 & Febrero & 29 & $\begin{array}{l}\text { La } \\
\text { Jornada }\end{array}$ & $\begin{array}{l}\text { Se piensa } \\
\text { que la } \\
\text { migración } \\
\text { externa es } \\
\text { causa de la } \\
\text { inseguridad: } \\
\text { CONAPRED }\end{array}$ & $\begin{array}{l}\text { En la población en } \\
\text { general, casi } 7 \text { de } \\
\text { cada } 10 \text { encuestados } \\
\text { consideran que los } \\
\text { inmigrantes } \\
\text { proporcionan } \\
\text { divisiones y } 27 \text { por } \\
\text { ciento no aceptaría } \\
\text { que en su casa } \\
\text { vivieran extranjeros. }\end{array}$ & 10 & $\begin{array}{l}10 \\
(1)= \\
10\end{array}$ & $\begin{array}{l}10 \\
(0== \\
0\end{array}$ & $\begin{array}{l}10 \\
(0)= \\
0\end{array}$ & 20 \\
\hline 2012 & Febrero & 29 & $\begin{array}{l}\text { La } \\
\text { Jornada }\end{array}$ & $\begin{array}{l}\text { Se piensa } \\
\text { que la } \\
\text { migración } \\
\text { externa es } \\
\text { causa de la } \\
\text { inseguridad: } \\
\text { CONAPRED }\end{array}$ & $\begin{array}{l}\text { Por el riesgo de que } \\
\text { las autoridades } \\
\text { mexicanas los } \\
\text { expulsen del país y el } \\
\text { desconocimiento de } \\
\text { sus derechos, éste } \\
\text { grupo de población no } \\
\text { acude a denunciar los }\end{array}$ & 3 & $\begin{array}{l}3(0) \\
=0\end{array}$ & $\begin{array}{l}3(2) \\
=6\end{array}$ & $\begin{array}{l}3(0) \\
=0\end{array}$ & 9 \\
\hline
\end{tabular}




\begin{tabular}{|c|c|c|c|c|c|c|c|c|c|c|}
\hline & & & & & $\begin{array}{l}\text { abusos de que son } \\
\text { objetos. }\end{array}$ & & & & & \\
\hline 2012 & Febrero & 20 & $\begin{array}{l}\text { La } \\
\text { Jornada }\end{array}$ & $\begin{array}{l}\text { México no es } \\
\text { único } \\
\text { responsable } \\
\text { de maltrato a } \\
\text { migrantes del } \\
\text { sur }\end{array}$ & $\begin{array}{l}\text { En ninguna parte del } \\
\text { mundo "se da una } \\
\text { situación en la cual el } \\
\text { migranter va } \\
\text { caminando entre } \\
\text { algodones desde su } \\
\text { país natal hasta el de } \\
\text { destino. No hay una } \\
\text { supercarretera donde } \\
\text { reciba trato bussines } \\
\text { class", asevera el } \\
\text { subsecretario para } \\
\text { América Latina y el } \\
\text { Caribe de la Secretaria } \\
\text { de Relaciones } \\
\text { Exteriores Rubén } \\
\text { Alberto Beltrán } \\
\text { Guerrero, al rechazar } \\
\text { que México sea el } \\
\text { único responsable por } \\
\text { la violación de los } \\
\text { derechos humanos de } \\
\text { los migrantes } \\
\text { centroamericanos en } \\
\text { su trayecto hacia } \\
\text { Estados Unidos. }\end{array}$ & 5 & $\begin{array}{l}5 \quad(1) \\
=5\end{array}$ & $\begin{array}{l}5 \quad(2) \\
=10\end{array}$ & $\begin{array}{l}5(3) \\
=15\end{array}$ & 35 \\
\hline 2012 & Febrero & 20 & $\begin{array}{l}\text { La } \\
\text { Jornada }\end{array}$ & $\begin{array}{l}\text { México no es } \\
\text { único } \\
\text { responsable } \\
\text { de maltrato a } \\
\text { migrantes del } \\
\text { sur }\end{array}$ & $\begin{array}{l}\text { La matanza de los } 72 \\
\text { migrantes en } \\
\text { Tamaulipas y las } \\
\text { denuncias de maltrato } \\
\text { en el trayecto hacia } \\
\text { Estados Unidos (...) } \\
\text { pero los coyotes } \\
\text { operan desde el lugar } \\
\text { de origen. El migrante } \\
\text { ya viene extorsionado, } \\
\text { enganchado desde su } \\
\text { país; desde allá viene } \\
\text { con las células del } \\
\text { crimen organizado. No } \\
\text { es que llegue a México } \\
\text { y todo se lo lleve la } \\
\text { fregada. }\end{array}$ & 5 & $\begin{array}{l}5(1) \\
=5\end{array}$ & $\begin{array}{l}5(2) \\
=10\end{array}$ & $\begin{array}{l}5(3) \\
=15\end{array}$ & 35 \\
\hline 2012 & Abril & 16 & $\begin{array}{l}\text { La } \\
\text { Jornada }\end{array}$ & $\begin{array}{l}\text { Sufren } \\
\text { migrantes } \\
\text { desempleo, } \\
\text { inseguridad y } \\
\text { violación de } \\
\text { derechos. }\end{array}$ & $\begin{array}{l}\text { Cuatro de cada } 10 \\
\text { personas de la } \\
\text { población mexicana } \\
\text { consideran que no se } \\
\text { respetan los derechos } \\
\text { de los migrantes. } \\
\text { Indicó que el } 20.5 \text { por } \\
\text { ciento de las personas } \\
\text { migrantes considera } \\
\text { que el principal } \\
\text { problema que } \\
\text { enfrentan por su }\end{array}$ & 3 & $\begin{array}{l}3(1) \\
=3\end{array}$ & $\begin{array}{l}3(0) \\
=0\end{array}$ & $\begin{array}{l}3(0) \\
=0\end{array}$ & 6 \\
\hline
\end{tabular}




\section{Inseguridad - Migración - Ciclo - Contextualización - Intensificación}

\begin{tabular}{|c|c|c|c|c|c|c|c|c|c|c|}
\hline & & & & & $\begin{array}{l}\text { condición migratoria } \\
\text { es la discriminación; } \\
\text { sólo por debajo del } 23 \\
\text { por ciento que opina } \\
\text { que son las } \\
\text { situaciones que se } \\
\text { relacionan con el } \\
\text { desempleo, mientras } \\
\text { que } 17 \text { por ciento } \\
\text { respondió que es la } \\
\text { inseguridad. }\end{array}$ & & & & & \\
\hline 2012 & Abril & 16 & $\begin{array}{l}\text { La } \\
\text { Jornada }\end{array}$ & $\begin{array}{l}\text { Mantiene } \\
\text { Solalinde } \\
\text { demandas } \\
\text { urgentes a } \\
\text { favor de } \\
\text { migrantes }\end{array}$ & $\begin{array}{l}\text { Los desequilibrios } \\
\text { económicos, la } \\
\text { desigualdad social y la } \\
\text { falta de autoridades } \\
\text { en sus lugares de } \\
\text { origen son las causas } \\
\text { que provocan la } \\
\text { migración. }\end{array}$ & 5 & $\begin{array}{l}5 \quad(1) \\
=5\end{array}$ & $\begin{array}{l}5 \quad(2) \\
=10\end{array}$ & $\begin{array}{l}5(0) \\
=0\end{array}$ & 20 \\
\hline 2012 & Febrero & 15 & $\begin{array}{l}\text { El } \\
\text { Universal }\end{array}$ & $\begin{array}{l}\text { Migrantes de } \\
\text { Hidalgo } \\
\text { permanecen } \\
\text { en EU por } \\
\text { miedo e } \\
\text { inseguridad }\end{array}$ & $\begin{array}{l}\text { Migrantes prefieren } \\
\text { quedarse en la Unión } \\
\text { Americana, ya que } \\
\text { después es más difícil } \\
\text { regresar a Estados } \\
\text { Unidos debido a las } \\
\text { duras leyes } \\
\text { migratorias como las } \\
\text { de Arizona y Alabama. }\end{array}$ & 7 & $\begin{array}{l}7 \quad(1) \\
=7\end{array}$ & $\begin{array}{l}7(2) \\
=14\end{array}$ & $\begin{array}{l}7(0) \\
=0\end{array}$ & 28 \\
\hline Total & & & & & & 58 & 55 & 58 & 42 & 208 \\
\hline
\end{tabular}

Fuente: Elaborada con los datos del estudio

Nota: El valor de cada noticia es determinado por su nulidad $=0$, agresión $=1$, injuria $=2$, injusticia $=3$, ansiedad $=4$, peligro $=5$, desesperación $=6$, pánico $=7$, depresión $=8$, venganza $=9$ y discriminación $=10$. Cada valor es multiplicado por su contextualización $=1$, enmarcado $=2$ e intensificación $=3$ del extracto periodístico. Al final se suman los productos y se establece el Índice de Mediatización de la Inseguridad Migratoria 